\title{
LA CONSTITUCIÓN EUROPEA: FORMA Y CONTENIDO, CIUDADANOS Y ESTADOS EN LA CONSTRUCCIÓN DEL SISTEMA DE FUENTES DE LA UNIÓN EUROPEA
}

FRANCISCO BALAGUER CALLEJÓN 


\section{SUMARIO}

1. FoRMA Y CONTENIDO, CIUDADANOS Y ESTADOS, ConstituCIÓN Y TRATADO. 2. LA FORMULACIÓN DE LA CONSTITUCIÓN EUROPEA COMO TRATADO Y SU MANIFESTACIÓN EN EL SISTEMA DE FUENTES. 3. LA RUPTURA DE LA TENSIÓN DIALÉCTICA ENTRE CONSTITUCIÓN Y TRATADO EN EL PROCESO DE RATIFICACIÓN. 4. LA INCIDENCIA DE ESA TENSIÓN DIALÉCTICA EN LOS PROCEDIMIENTOS DE REFORMA DEL TRATADO CONSTITUCIONAL. 5. CONCLUSIONES. 


\title{
LA CONSTITUCIÓN EUROPEA: FORMA Y CONTENIDO, CIUDADANOS Y ESTADOS EN LA CONSTRUCCIÓN DEL SISTEMA DE FUENTES DE LA UNIÓN EUROPEA
}

POR

\author{
FRANCISCO BALAGUER CALLEJÓN
}

Catedrático de Derecho Constitucional de la Universidad de Granada y Catedrático Jean Monnet de Derecho Constitucional Europeo

\section{FORMA Y CONTENIDO, CIUDADANOS Y ESTADOS, CONSTITUCIÓN Y TRATADO}

El debate sobre la naturaleza jurídica del Tratado Constitucional, que nos parecía ya cerrado a muchos, en el sentido de que el Tratado Constitucional era simultáneamente una Constitución (por su contenido) y un Tratado (por su forma) ${ }^{1}$, ha vuelto a tomar fuerza en el proceso de ratificación debido a los resultados negativos de los procesos refrendatarios en Francia y Holanda. Naturalmente, el cuestionamiento del Tratado Constitucional se ha producido no sólo por su forma de Tratado sino también en relación con su contenido, respecto del cual el debate fundamental ha girado en torno a lo limitado del carácter constitucional del Tratado.

${ }^{1}$ Cfr. mi trabajo «El sistema de fuentes en la Constitución Europea», Revista de Derecho Constitucional Europeo, n. ${ }^{\circ}$ 2, julio-diciembre de 2004, pp. 61-79. 
Este limitado carácter constitucional es comprensible, sin embargo, desde la consideración dinámica del proceso de constitucionalización de la Unión Europea. No es pensable que Europa pueda dar un salto en el vacío y avanzar más allá de sus condiciones objetivas superando los obstáculos que dificultan el establecimiento de un modelo constitucional congruente con su estructura territorial y su composición social ${ }^{2}$. Por ese motivo no parece que el debate actual sobre si el Tratado es una opción a descartar o sigue todavía siendo una opción válida, pueda avanzar mucho. Si no es este Tratado Constitucional, será una fórmula similar por lo que a su contenido se refiere. Cuestión distinta cabría decir hoy, en relación con la forma.

El contenido no puede variar sustancialmente porque en el estado actual del proceso de integración no es posible retroceder ni tampoco cabe mantener la situación como está. Es necesario avanzar en muchos ámbitos para hacer congruente el nivel de desarrollo del poder político de la Unión con las exigencias del sistema democrático de los Estados miembros que han transferido competencias propias a la Unión. Esta necesidad resulta especialmente evidente en relación con la Carta de Derechos Fundamentales, que no puede permanecer indefinidamente en stand by como lleva ya varios años.

El problema, sin embargo, es que tampoco resulta posible avanzar en contenidos constitucionales aislados como si el Derecho constitucional no fuera un conjunto de técnicas y de equilibrios y se pudieran elegir aquéllos que parezcan más oportunos en cada momento. Un ejemplo claro lo tenemos justamente con los Derechos Fundamentales. No se puede dar plena vigencia a la Carta de Derechos Fundamentales sin realizar cambios importantes en el orden institucional y en el de los instrumentos normativos. La Carta de Derechos contiene reservas de ley tanto para desarrollar como para limitar los derechos que exigen la implantación de un sistema de fuentes en el que se incorpore la forma legal.

Si el contenido debe seguir siendo básicamente constitucional, se nos plantea entonces la cuestión de la forma. A este respecto creo que se puede establecer un cierto paralelismo entre los agentes que el propio Tratado Constitucional identifica y la tensión que se refleja en todo el sistema de fuentes, comenzando por la propia Constitución. Esos agentes no son otros que los ciudadanos y los Estados, la doble fuente

2 Cfr. mi trabajo. «Die europäische Verfassung auf dem Weg zum Europäischen Verfassungsrecht" Jahrbuch des öffentlichen Rechts der Gegenwart, Mohr Siebeck, Tübingen, Bd. 53, 2005, pp. 401-410. 
de legitimación de la Unión ${ }^{3}$. Podríamos decir que la tensión entre ciudadanos y Estados es también la que ha dado lugar a esta figura peculiar de Tratado y Constitución, la que ha conducido a la forma de Tratado y al contenido de Constitución. Igualmente, esa tensión vertebra todo el sistema institucional y el sistema de fuentes (este último será objeto de análisis en este trabajo) y, por tanto, el contenido constitucional del Tratado, cuyas deficiencias desde la perspectiva constitucional se derivan de la orientación todavía muy acusada hacia los Estados. Pese a ello $y$, aunque se podía haber avanzado más, se trata de un contenido constitucional adecuado para la situación actual de la Unión Europea, en cuanto punto de partida de futuras evoluciones. Al menos, con carácter general: otra cosa se puede decir del procedimiento de ratificación y de los procedimientos de reforma, esto es, del nivel relativo a la fuente "Constitución» como tal, afectada justamente por la quiebra de su lógica interna que supone la forma de Tratado.

Ni que decir tiene que esa quiebra es la más importante que podía darse, por cuanto que, de confirmarse la inviabilidad de la ratificación del Tratado Constitucional, ello debería conducir a plantearse la necesidad de una Constitución que lo sea no sólo por su contenido sino también por su forma, evitando procedimientos convencionales de carácter internacional y articulando procedimientos constitucionales.

\section{LA FORMULACIÓN DE LA CONSTITUCIÓN EUROPEA COMO TRATADO Y SU MANIFESTACIÓN EN EL SISTEMA DE FUENTES}

La vertiente convencional de la Constitución Europea incide claramente en la formulación del sistema de fuentes. El hecho de que los Estados sean los actores del proceso constituyente no supone que el resultado final de ese proceso no sea una auténtica Constitución. Un pacto federal también da lugar a una Constitución, máxime cuando ese pacto es adoptado por órganos democráticos y sometido a ratificación posterior en cada Estado. Cuestión distinta es la del grado de de-

${ }^{3}$ Esa doble legitimación se refleja ya en el Preámbulo de la Constitución cuando se afirma que la Convención ha elaborado la Constitución "en nombre de los ciudadanos y de los Estados de Europa». Se manifiesta también en el artículo I-1.1: «1. La presente Constitución, que nace de la voluntad de los ciudadanos y de los Estados de Europa de construir un futuro común...". Se refleja, además, en el plano orgánico e institucional, cuando el artículo 46,2 dice: "Los ciudadanos estarán directamente representados en la Unión a través del Parlamento Europeo. Los Estados miembros estarán representados en el Consejo Europeo por su Jefe de Estado o de Gobierno y en el Consejo por sus Gobiernos». 
sarrollo de ese pacto, que no es propiamente federal, y del Derecho constitucional de que pueden dotarse los Estados actualmente en el proceso de integración europea, si tenemos en cuenta los factores que dificultan un desarrollo similar al de los órdenes constitucionales internos (en relación con el tipo de Constitución adecuada al proceso de integración $)^{4}$. Más allá de las dificultades objetivas, no puede dejar de señalarse que posiblemente los Estados podían haber avanzado más en el proceso de constitucionalización, para corresponder así a los deseos de los ciudadanos.

Comoquiera que la Constitución es el factor regulador del sistema de fuentes, los déficits constitucionales se reflejan necesariamente en el conjunto del sistema. La clarificación del poder último regulador, de la "norma fundamental» del sistema, por utilizar los términos kelsenianos ${ }^{5}$ es importante para determinar las relaciones internas entre las fuentes, su régimen jurídico, y las relaciones con los ordenamientos estatales. A medida que avance el proceso de constitucionalización y se clarifique este extremo fundamental, se podrá ir simplificando el sistema y ganando en seguridad jurídica.

Como se puede comprender, la clarificación y sistematización no depende sólo de las soluciones que se aporten en relación con el sistema de fuentes. Por el contrario, los aspectos institucionales y competenciales mediatizan la eficacia de las transformaciones del sistema de fuentes. Esto se explica porque, en realidad, forman parte, en sentido amplio, del sistema de fuentes, por cuanto que integran el sistema de normas sobre la producción jurídica que conforma la "Constitución material", en el sentido kelseniano de este término ${ }^{6}$. Debe dejarse señalado, en todo caso, que no es pensable que el sistema deje de tener la condición singularmente dinámica que le ha caracterizado desde su nacimiento y especialmente en los últimos años. Puesto que las transformaciones institucionales y competenciales inciden en el sistema de fuentes, cabe esperar que haya transformaciones no sólo endógenas sino también exógenas. De hecho, esa virtualidad para adaptarse a las necesidades externas ha estado en la base de la proliferación de actos jurídicos previa a la Constitución, para prefigurar o para dar respuesta

\footnotetext{
4 A este respecto, me remito a mi trabajo "Die europäische Verfassung auf dem Weg zum Europäischen Verfassungsrecht», cit.

5 Cfr. al respecto mi trabajo Fuentes del Derecho, Tecnos, Madrid, 1991 y 1992.

${ }^{6}$ Cfr. Reine Rechstlehre, 2. a edición, de 1960, Franz Deuticke, Viena, reimpresión de 1967, p. 228: "Verfassung wird hier in einem materiellen Sinn, das heißt: mit diesem Worte wird die positive Norm oder die positiven Normen verstanden, durch die Erzeugung der generellen Rechtsnormen geregelt wird".
} 
a nuevas necesidades competenciales ${ }^{7}$. Naturalmente, la cualidad de las transformaciones dependerán mucho de la circunstancias externas y especialmente de la implantación del Tratado Constitucional o de un texto constitucional similar.

El intento de acomodar el sistema de fuentes a categorías constitucionales comienza con la creación de la Ley europea y la Ley marco europea que vienen a sustituir a las Directivas (Ley marco europea) y a los Reglamentos comunitarios (Ley europea). De acuerdo con lo dispuesto en el artículo I-33.1, segundo párrafo, "La ley europea es un acto legislativo de alcance general. Será obligatoria en todos sus elementos y directamente aplicable en cada Estado miembro". Por su parte, el tercer párrafo define a la Ley marco: "La ley marco europea es un acto legislativo que obliga al Estado miembro destinatario en cuanto al resultado que deba conseguirse, dejando, sin embargo, a las autoridades nacionales la competencia de elegir la forma y los medios".

Como hemos indicado, la homologación con los sistemas constitucionales era necesaria, entre otros motivos, por la incorporación de la Carta de Derechos Fundamentales a la Constitución, que exigía un legislador de los derechos fundamentales para conformarlos, desarrollarlos e incluso para limitarlos ${ }^{8}$. La asunción de categorías constitucionales va unida a una amplia previsión de reservas de ley establecidas en diversos apartados de la Constitución. Ahora bien, ni la reserva de ley, ni la ley expresan en el ordenamiento europeo el sentido que tienen en los ordenamientos estatales. La contraposición básica entre mayoría y minorías es la que fundamenta en los ordenamientos internos la reserva de ley, en cuanto la ley es expresión de las garantías formales que hacen posible la expresión del pluralismo ${ }^{9}$. A través de los procedimientos legales (no siempre parlamentarios, como ocurre cuando existen actos con valor de ley, como los decretos-leyes o los decretos legislativos) se hace posible la participación de las minorías en la producción legislativa y/o en su control.

La contraposición mayoría-minorías exige, sin embargo, un espacio público desarrollado dentro de una comunidad política consolidada. No

7 Cfr., al respecto, A.v.Bogdandy, J. Bast y F. Arndt «Tipología de los actos en el Derecho de la Unión Europea. Análisis empírico y estructuras dogmáticas en una presunta jungla», REP, n. 123, enero-marzo de 2004.

8 Baste mencionar aquí el artículo II-112.1: "Cualquier limitación del ejercicio de los derechos y libertades reconocidos por la presente Carta deberá ser establecida por la ley y respetar el contenido esencial de dichos derechos y libertades".

9 Cfr. mi trabajo Fuentes del Derecho, cit., vol. II, pp. 54 y ss. 
es el caso, todavía, de la Unión Europea, donde la tensión constitucional que se manifiesta en los procesos normativos de nivel superior no es la de mayoría-minorías. Por el contrario, esa tensión se refleja en otras variables que expresan en última instancia la doble legitimidad sobre la que descansa la Unión: la de los ciudadanos y la de los Estados. Esta dialéctica se traslada a una muy pormenorizada relación de competencias constitucionales de los órganos conectada a la diversidad de ámbitos competenciales de la Unión Europea. El resultado de este tipo de técnicas es que se desdibujan los caracteres típicos de la ley en los ordenamientos estatales. Así por ejemplo, no se reconoce una potestad general al poder legislativo ${ }^{10}$ ni tampoco existe una habilitación para que el legislador supla los supuestos en que no haya previsión constitucional del tipo de fuente que debe utilizarse ${ }^{11}$. Tampoco se percibe de una manera clara la articulación jerárquica entre la ley y el reglamento, a través de un concepto como el de fuerza de ley. De hecho, junto a las reservas establecidas para la ley en la Constitución, existen otras reservas para reglamentos y para otros tipos de actos ${ }^{12}$. Por otro lado, la previsión de una vinculación directa entre la Constitución y el reglamento forma parte también de las previsiones del Tratado, de tal manera que se consolida un tipo de reglamento (el reglamento independiente $)^{13}$ que no es aceptado en muchos ordenamientos estatales basados en un sistema parlamentario de gobierno ${ }^{14}$. No queda claro, en

10 Por el contrario, cabe hablar de la existencia de "reservas negativas de ley", además de reservas específicas de reglamento, como ocurre con el artículo 1-40.6, relativo a la política exterior y de seguridad común, en el que se indica rotundamente que "Las leyes y leyes marco europeas no se utilizarán en esta materia".

11 De hecho el artículo l-38.1 prevé que "Cuando la Constitución no establezca el tipo de acto que deba adoptarse, las instituciones decidirán en cada caso conforme a los procedimientos aplicables y al principio de proporcionalidad contemplado en el artículo I-11".

12 Ejemplos de estas previsiones de desarrollo reglamentario se pueden encontrar, por ejemplo, en los artículos III-190.3, III-266.3, III-400, III-412.2, III-428 o III-433.

13 Ejemplos de este tipo de reglamentos se pueden encontrar, por ejemplo, en los artículos III-163, III-183.2, III-198.3, III-240.3, III-253 y III-263.

14 De necesaria incorporación, sin embargo, en el texto constitucional a tenor de las manifestaciones del representante de la Comisión en el Grupo de Trabajo IX, sobre simplificación de los procedimientos e instrumentos: "La fonction dite "exécutive" ne s'épuise pas avec l'exécution des lois. En effet, dans certains cas, la mise en oeuvre de certaines politiques prévues par le traité ne requiert pas d'intervention du Législateur. II s'agit des actes de la PESC, définissant la politique de I'UE vis-à-vis des Etats tiers, de certains actes en matière de police, ainsi que des actes concernant le fonctionnement de l'Union économique et monétaire, qui visent à réagir à des situations qui ne se prêtent pas à une réglementation antérieure de type législatif. Dans ces domaines, il convient de prévoir dans le texte constitutionnel un rôle 
todo caso, en que medida podría el legislador sobreponer sus mandatos a este tipo de fuentes en esos ámbitos ${ }^{15}$.

La delimitación de tipos legislativos está también relacionada con la compleja estructura institucional de la Unión. Junto a las leyes o leyes marco que siguen el procedimiento legislativo ordinario (codecisión) ${ }^{16}$ que tiene carácter general, están también las que siguen los procedimientos legislativos especiales ${ }^{17}$ y que dan lugar a leyes del Consejo ${ }^{18} \mathrm{y}$ leyes del Parlamento ${ }^{19}$.

Todas estas peculiaridades son indicativas de que estamos todavía ante un proceso abierto que requerirá de nuevas operaciones de simplificación y sistematización conforme vayan madurando el espacio público y la comunidad constitucional europea. Ese proceso estará condicionado por la ampliación de los ámbitos competenciales y por las modificaciones en la estructura institucional.

Similares reflexiones pueden realizarse en relación con el reglamento europeo que adquiere, en parte, un significado peculiar en consonancia con las características señaladas del sistema de fuentes y la conformación de la ley: «El reglamento europeo es un acto no legislativo de alcance general que tiene por objeto la ejecución de actos legislativos y de determinadas disposiciones de la Constitución. Podrá bien ser obligatorio en todos sus elementos y directamente aplicable en

\footnotetext{
"autonome" de I'“Exécutif". Vu le caractère spécifique des matières concernées, la Commission propose que ces compétences continuent, à titre exceptionnel, à relever du Conseil sur proposition de la Commission (voire, le cas échéant, des Etats membres). II est entendu que si les décisions du Conseil dans ces domaines requièrent une exécution au niveau européen, le schéma précédent (exécution par la Commission) devrait s'appliquer".

15 Hay que tener en cuenta, además, el artículo I-38.2 que remite a las previsiones constitucionales tasadas el ejercicio de las competencias normativas: "Los actos jurídicos deberán estar motivados y se referirán a las propuestas, iniciativas, recomendaciones, peticiones o dictámenes previstos por la Constitución".

${ }^{16}$ Art. I-34.1: «Las leyes y leyes marco europeas serán adoptadas, a propuesta de la Comisión, conjuntamente por el Parlamento Europeo y el Consejo por el procedimiento legislativo ordinario contemplado en el artículo III-396. Si ambas instituciones no llegan a un acuerdo, el acto no se adoptará».

17 Art. I-34.2: «En los casos específicos previstos por la Constitución, las leyes y leyes marco europeas serán adoptadas por el Parlamento Europeo con la participación del Consejo, o por éste con la participación del Parlamento Europeo, con arreglo a procedimientos legislativos especiales".

${ }_{18}$ Cfr. por ejemplo, los artículos I-54.3 y 4, I-55.2, III-124.1, III-125.2, III-126, III-127, III-129, III-157.3.

${ }_{19}$ Cfr. los artículos III-330.2, III-333 y III-335.4.
} 
cada Estado miembro, o bien obligar al Estado miembro destinatario en cuanto al resultado que deba conseguirse, dejando, sin embargo, a las autoridades nacionales la competencia de elegir la forma y los medios".

En lo que se refiere al reglamento que podríamos calificar como «independiente", se trata de un significado poco habitual en la formulación tradicional de las fuentes del Derecho (con algunas excepciones nacionales, por otro lado), donde el reglamento tiene siempre la finalidad de ejecutar los actos legislativos y no directamente disposiciones particulares de la Constitución. Es, sin embargo, como hemos indicado, un tipo normativo sobre el que existía una específica voluntad de incorporarlo al texto constitucional y que tiene su reflejo en diversas disposiciones constitucionales ${ }^{20}$.

Por otro lado, tampoco es habitual que el reglamento no sea una norma obligatoria en todos sus elementos. Por tanto, esta especie de reglamento-marco que se crea en el Proyecto $\mathrm{CEu}$ tiene poco sentido desde el entendimiento habitual del reglamento y puede generar confusión entre los aspectos competenciales y los normativos.

Estos dos tipos de reglamentos (los de ejecución directa de la Constitución y los reglamentos "marco", por definirlos de alguna manera) son figuras que tienen nuevamente relación con la complejidad institucional y con la incidencia del sistema competencial en la ordenación de las fuentes. En su formulación tradicional, el reglamento debe ser una norma subordinada a la ley y eso significa que es la ley la que debe desarrollar la Constitución, por un lado, y que es también la ley la que debe establecer el marco de actuación del reglamento, por el otro. Estos dos principios se rompen con la ambigua caracterización del reglamento que se contiene en el Proyecto y que se manifiesta también en la dificultad para precisar cual va a ser el alcance de las facultades normativas a disposición del poder reglamentario.

Hay que tener en cuenta también que se incorporan al texto constitucional remisiones específicas al reglamento que pueden considerarse como auténticas reservas de reglamento lo que, si bien se da en algunos sistemas constitucionales, no deja de complicar las relaciones entre ley y reglamento y dificultar una diferenciación más nítida entre el nivel legislativo y el reglamentario.

20 V. nota 14. 


\section{LA RUPTURA DE LA TENSIÓN DIALÉCTICA ENTRE CONSTITUCIÓN Y TRATADO EN EL PROCESO DE RATIFICACIÓN}

La tensión que el Tratado Constitucional expresa entre ciudadanos y Estados y que se refleja en el sistema de fuentes, como hemos podido apreciar, se ha venido a romper justamente en el proceso de ratificación diseñado en la propia Constitución.

Si algo ha puesto de relieve el referéndum en Francia y en Holanda, es que en una Europa de 25 (27) miembros no es posible seguir pensando en avances constitucionales significativos sobre la base de la ratificación de tratados por los Estados miembros. A pesar de que la Constitución ha sido ya ratificada por más de la mitad de los Estados, que representan a más de la mitad de los ciudadanos europeos, el golpe "democrático" que ha supuesto la negativa de dos Estados fundadores mediante el voto contrario en referéndum ha situado al proceso de ratificación en una posición muy difícil. El choque de legitimidades entre los Estados y los ciudadanos resulta inevitable cuando los procesos de ratificación combinan (como ha sido el caso) consultas populares con votaciones parlamentarias. Mientras que en otros muchos aspectos es aceptable el equilibrio constitucional entre ciudadanos y Estados (siempre que ese equilibrio se vaya ajustando de manera dinámica hacia los ciudadanos y hacia la construcción de una comunidad constitucional europea), en materia de ratificación la fragilidad de ese equilibrio ha quedado en evidencia. En este ámbito bien se podría decir: o los ciudadanos o los Estados, lo que en otros términos equivale a: o la Constitución o el Tratado.

Desde esa perspectiva, hay que considerar que el cuestionamiento del Tratado Constitucional en Francia y en Holanda (al menos en los sectores democráticos que han votado "no" en el referéndum) no parece haberse planteado en relación con su vertiente constitucional, sino en relación con su forma de Tratado. En efecto, lo que ha quedado en cuestión, no es el contenido constitucional del Tratado, ya que todo parece indicar que las voces críticas que, dentro de los sectores democráticos, han dado lugar a un resultado desfavorable no pedían «menos Constitución», sino "más Constitución». Por tanto, lo que ha resultado discutido y lo que debe someterse a revisión es su forma. Lo que parece inaceptable a muchos europeos es que a estas alturas del proceso de integración todavía sea necesario utilizar la forma de tratado para algo que, en principio, requeriría no sólo un contenido constitucional (acaso más intenso) sino también una forma constitucional.

Incluso si se parte de la base de que la operación de presentar como "Constitución" un texto que no lo era íntegramente (siquiera 
por su forma de Tratado) ha defraudado a los europeos que se han manifestado en contra, parece que la conclusión que podemos extraer no es ofrecerles un nuevo Tratado sino la de darles realmente lo que querían: una Constitución. Para darles una Constitución es necesario romper el equilibrio entre ciudadanos y Estados que se manifiesta en la formulación de la Constitución como un Tratado y asumir la necesidad de que la Constitución lo sea no sólo por su contenido sino también por su forma. Este sería sin duda, un gran paso adelante en el proceso de integración, un paso definitivo. Lo sería porque, aunque por el contenido constitucional no se avanzara tanto en lo que se refiere a la orientación de las instituciones y los procedimientos hacia la esfera de los ciudadanos (en la tensión dialéctica ciudadanos-Estados) sí sería posible conseguir esos avances en el futuro sin que la mera negativa de uno o varios Estados pudiera ser un obstáculo insalvable.

De ese modo, aunque el contenido de la Constitución siguiera estando condicionado por la sustantividad de los Estados y por mecanismos de decisión interestatales, los avances constitucionales necesarios podrían basarse en un esquema constitucional, más ágil y más coherente con la idea de una comunidad constitucional europea. Para ello, no debería abordarse solamente la cuestión de la aprobación de la Constitución, sino también la de su reforma, por cuanto ésta sigue siendo la fuente formal de renovación de la Constitución (por más que no sea la única vía a través de la cual la Constitución se adapta a las necesidades constitucionales de la sociedad) ${ }^{21}$.

\section{LA INCIDENCIA DE ESA TENSIÓN DIALÉCTICA EN LOS PROCEDIMIENTOS DE REFORMA DEL TRATADO CONSTITUCIONAL}

Los procedimientos de revisión del Tratado Constitucional son expresivos también de la dificultad que supone conciliar la tensión dialéctica entre ciudadanos y Estados en el nivel específicamente constitucional. Por un lado, el Tratado ha intentado flexibilizar en lo posible los procedimientos de reforma introduciendo un diverso grado de formalización y de rigidez, en función de las materias.

En algunos casos la desformalización es total, si bien se trata de supuestos que más bien podrían haberse incluido en disposiciones transi-

${ }^{21}$ Cfr. CARLOS DE CABo MARTín, La reforma constitucional en la perspectiva de las fuentes del Derecho, Trotta, Madrid, 2003. Sobre los procedimientos de revisión del Tratado Constitucional, cfr. Manuel Contreras CASADo, "La reforma del Tratado Constitucional», ReDCE, n. 2, julio-diciembre de 2004, pp. 149 y ss. 
torias por su contenido, ya que son ejemplos típicos de derecho transitorio que pretenden fijar un régimen especial para determinadas situaciones durante un cierto periodo de tiempo, hasta que las previsiones constitucionales puedan aplicarse de manera general. Si estos preceptos se hubieran incorporado como disposiciones transitorias, con una correcta técnica legislativa, no habría sido necesaria la derogación de los correspondientes apartados, ya que la decisión europea del Consejo se habría limitado a declarar que había terminado ya ese periodo transitorio y que en lo sucesivo, las ayudas estatales directas ${ }^{22} \mathrm{o}$ indirectas ${ }^{23}$ podrían considerarse incompatibles con el mercado interior.

Un supuesto distinto al anterior, pero que supone igualmente una modificación del texto constitucional es el contemplado en el artículo 440.7, en virtud del cual, «El Consejo Europeo, por iniciativa del Estado miembro de que se trate, podrá adoptar una decisión europea que modifique el estatuto respecto de la Unión de alguno de los países o territorios daneses, franceses o neerlandeses a que se refieren los apartados 2 y 3 . El Consejo Europeo se pronunciará por unanimidad, previa consulta a la Comisión».

${ }^{22}$ Es el caso de la previsión del apartado c) del artículo 167.2 CEu, en virtud del cual, se consideran compatibles con el mercado interior, «c) las ayudas concedidas para favorecer la economía de determinadas regiones de la República Federal de Alemania afectadas por la división de Alemania, en la medida en que sean necesarias para compensar las desventajas económicas ocasionadas por esta división. Cinco años después de la entrada en vigor del Tratado por el que se establece una Constitución para Europa, el Consejo podrá adoptar, a propuesta de la Comisión, una decisión europea por la que se derogue la presente letra». Como se puede ver, se trata de una deficiente técnica legislativa, ya que este supuesto no debería haberse incorporado al articulado de la Constitución sino que debería figurar como una mera disposición transitoria pues en estos casos se excepciona transitoriamente para los Länder de la antigua Alemania del Este la incompatibilidad de las ayudas estatales con el mercado interior.

${ }^{23}$ Una previsión similar se encuentra en el artículo $243 \mathrm{CEu}$, en relación con el establecimiento por Alemania de precios y condiciones de transportes que supongan ayudas a determinadas empresas. En virtud de ese artículo, "Las disposiciones de la presente Sección no obstarán a las medidas adoptadas en la República Federal de Alemania, en la medida en que sean necesarias para compensar las desventajas económicas ocasionadas por la división de Alemania a la economía de determinadas regiones de la República Federal afectadas por esta división. Cinco años después de la entrada en vigor del Tratado por el que se establece una Constitución para Europa, el Consejo podrá adoptar, a propuesta de la Comisión, una decisión europea por la que se derogue el presente artículo". Se trata también de un supuesto de derecho transitorio que si se hubiera formulado como disposición transitoria no habría requerido esta modificación del texto constitucional mediante la derogación de un artículo. 
En el otro extremo del nivel de formalización y rigidez se sitúan los procedimientos de revisión previstos en los artículos 443, 444 y 445. En el artículo 443, se establece el procedimiento de revisión general, bajo el título de "procedimiento de revisión ordinario» ${ }^{24}$. En realidad, no se trata de un solo procedimiento, ya que este precepto prevé al menos dos posibilidades, dependiendo de que se convoque o no una convención. De acuerdo con este artículo, la iniciativa de la revisión corresponde a los gobiernos de los Estados miembros, al Parlamento Europeo y a la Comisión, que presentarán al Consejo los proyectos de revisión para que los remita al Consejo Europeo y los notifique a los Parlamentos nacionales. El Consejo Europeo es el encargado de determinar si la revisión es procedente, ya que, previa consulta al Parlamento Europeo y a la Comisión podrá adoptar por mayoría simple una decisión favorable al examen de las modificaciones propuestas. A partir de ese momento, el Presidente del Consejo Europeo convocará una Convención (siguiendo el modelo de la Convención Europea que ela-

24 «1. El Gobierno de cualquier Estado miembro, el Parlamento Europeo o la Comisión podrán presentar al Consejo proyectos de revisión del presente Tratado. El Consejo remitirá dichos proyectos al Consejo Europeo y los notificará a los Parlamentos nacionales.

2. Si el Consejo Europeo, previa consulta al Parlamento Europeo y a la Comisión, adopta por mayoría simple una decisión favorable al examen de las modificaciones propuestas, el Presidente del Consejo Europeo convocará una Convención compuesta por representantes de los Parlamentos nacionales, de los Jefes de Estado o de Gobierno de los Estados miembros, del Parlamento Europeo y de la Comisión. Cuando se trate de modificaciones institucionales en el ámbito monetario, se consultará también al Banco Central Europeo. La Convención examinará los proyectos de revisión y adoptará por consenso una recomendación a una Conferencia de los representantes de los Gobiernos de los Estados miembros según lo dispuesto en el apartado 3.

El Consejo Europeo podrá decidir por mayoría simple, previa aprobación del Parlamento Europeo, no convocar una Convención cuando la importancia de las modificaciones no lo justifique. En este último caso, el Consejo Europeo establecerá un mandato para una Conferencia de los representantes de los Gobiernos de los Estados miembros.

3. Una Conferencia de los representantes de los Gobiernos de los Estados miembros será convocada por el Presidente del Consejo con el fin de que se aprueben de común acuerdo las modificaciones del presente Tratado.

Las modificaciones entrarán en vigor después de haber sido ratificadas por todos los Estados miembros de conformidad con sus respectivas normas constitucionales.

4. Si, transcurrido un plazo de dos años desde la firma del Tratado por el que se modifica el presente Tratado, las cuatro quintas partes de los Estados miembros lo han ratificado y uno o varios Estados miembros han encontrado dificultades para proceder a dicha ratificación, el Consejo Europeo examinará la cuestión». 
boró el Tratado Constitucional), salvo que el Consejo Europeo decida, por mayoría simple y previa aprobación del Parlamento Europeo, que no es necesaria convocar la Convención, porque la importancia de las modificaciones no lo justifique. En ese caso bastará con la convocatoria de una Conferencia Intergubernamental.

Si se convoca una Convención, ésta deberá examinar los proyectos de revisión y adoptar por consenso una recomendación a la Conferencia Intergubernamental. Como se puede ver, la función de la Convención no es aquí equiparable a la que desarrolló la Convención Europea para aprobar la Constitución, ya que la Convención se limita a analizar los proyectos elaborados por otras instancias y a informarlos, pero no elabora ella misma el proyecto, como hizo la Convención Europea con la Constitución. En ese sentido, se podría decir que el procedimiento de revisión ordinario es menos cercano a los parámetros constitucionales que el mecanismo que se utilizó para aprobar la Constitución. Máxime si se tiene en cuenta que ni siquiera es obligatoria la convocatoria de la Convención.

La Conferencia Intergubernamental deberá adoptar la revisión de común acuerdo y una vez que se apruebe, deberá ser ratificada por todos los Estados miembros de conformidad con sus respectivas normas constitucionales. Esta exigencia de ratificación nacional unánime sitúa al procedimiento ordinario de revisión en el ámbito del Derecho internacional, en cuanto modificación de un Tratado. Se sigue, por tanto, el procedimiento de ratificación del propio Tratado Constitucional sin que se avance en términos constitucionales.

Se plantean, por tanto, los mismos problemas que han surgido en el proceso de ratificación de la Constitución, a los que se da también la misma solución para el caso de que no todos los Estados ratifiquen la reforma, ya que el apartado 4 de este precepto ha previsto para ese supuesto que si transcurrido un plazo de dos años desde la firma del Tratado por el que se modifica el presente Tratado, las cuatro quintas partes de los Estados miembros lo han ratificado y uno o varios Estados miembros han encontrado dificultades para proceder a dicha ratificación, el Consejo Europeo examinará la cuestión. Esta previsión, que la Declaración 30 incorporada a la Constitución también aplica a la entrada en vigor inicial de la Constitución, hubiera podido suponer en el futuro un mayor acercamiento a parámetros constitucionales en la medida en que hiciera posible la entrada en vigor de la Constitución sin que todos los Estados la hubieran ratificado (con el riesgo inevitable de que eso suponga, al tiempo, la separación de algún Estado de la Unión) con la consiguiente presión a los Estados para que ratifiquen. Sin em- 
bargo, la experiencia negativa del proceso de ratificación del Tratado Constitucional evidencia que se trata de un paso absolutamente insuficiente y que puede generar los mismos problemas que ahora se están planteando en el proceso de ratificación.

Existen otros procedimientos de revisión que se caracterizan como simplificados y en los que ni se convoca una Convención ni una Conferencia Intergubernamental. Estos dos procedimientos están previstos para tres supuestos, referidos todos a la Parte III de la Constitución, que es la que se puede modificar por estas vías. Dos de ellos se contemplan en el artículo 444 y hacen referencia a dos tipos de modificaciones que se incluyen dentro de lo que se ha denominado "cláusulas pasarela ${ }^{25}$. La primera de esas cláusulas está orientada a hacer posible una mayor flexibilidad en la adopción de decisiones, de tal manera que se modifican aquellos ámbitos en los que se exige unanimidad por la Constitución para adoptar esas decisiones sustituyendo la unanimidad por mayoría cualificada (444.1), con el límite de aquellas disposiciones relativas a defensa o que tengan repercusiones militares. La segunda está orientada a racionalizar y democratizar los procedimientos legislativos, haciendo posible la sustitución de los procedimientos legislativos especiales previstos en la Constitución por procedimientos legislativos ordinarios (tanto para leyes europeas como para leyes marco europeas).

25 Artículo IV-444:

"Procedimiento de revisión simplificado.

1. Cuando la Parte III disponga que el Consejo se pronuncie por unanimidad en un ámbito o en un caso determinado, el Consejo Europeo podrá adoptar una decisión europea que autorice al Consejo a pronunciarse por mayoría cualificada en dicho ámbito o en dicho caso.

El presente apartado no se aplicará a las decisiones que tengan repercusiones militares o en el ámbito de la defensa.

2. Cuando la Parte III disponga que el Consejo adopte leyes o leyes marco europeas por un procedimiento legislativo especial, el Consejo Europeo podrá adoptar una decisión europea que autorice a adoptar dichas leyes o leyes marco por el procedimiento legislativo ordinario.

3. Cualquier iniciativa tomada por el Consejo Europeo en virtud de los apartados 1 o 2 se transmitirá a los Parlamentos nacionales. En caso de oposición de un Parlamento nacional notificada en un plazo de seis meses a partir de esta transmisión, no se adoptará la decisión europea contemplada en los apartados 1 o 2. A falta de oposición, el Consejo Europeo podrá adoptar la citada decisión.

Para la adopción de las decisiones europeas contempladas en los apartados 1 y 2, el Consejo Europeo se pronunciará por unanimidad, previa aprobación del Parlamento Europeo, que se pronunciará por mayoría de los miembros que lo componen". 
Estas cláusulas pasarela pueden activarse por el Consejo Europeo, mediante una decisión europea que debe ser adoptada por unanimidad previa aprobación del Parlamento Europeo por mayoría. Además, se requiere el consentimiento previo de todos los parlamentos nacionales de los Estados miembros, ya que se deberá toda iniciativa tomada por el Consejo Europeo para activar estas cláusulas deberá transmitirse a los Parlamentos nacionales y en caso de oposición de un Parlamento nacional notificada en un plazo de seis meses a partir de esta transmisión, no se adoptará la decisión europea.

Como se puede ver, en este procedimiento no existe, como en el procedimiento ordinario, una concertación internacional que exija que la revisión sea objeto de ratificación interna por cada uno de los Estados miembros. En lugar de eso, se configura una consulta previa a los parlamentos nacionales que, sin embargo, podría suponer una mayor dificultad para la aprobación de la revisión que la ratificación prevista para el procedimiento simplificado del artículo 444 (no puede decirse lo mismo respecto del procedimiento ordinario del 443, ya que en ese caso es necesario el acuerdo previo de todos los Estados a través de la Conferencia Intergubernamental). En todo caso, debe valorarse positivamente que este procedimiento culmine en una Decisión europea que es una norma de Derecho interno y, por tanto, de carácter constitucional y no internacional. Es desde esa perspectiva, el procedimiento más cercano a los parámetros constitucionales.

Por su parte, el artículo 445 contiene un procedimiento de revisión simplificado "relativo a las políticas y acciones internas de la Unión» ${ }^{26}$.

\footnotetext{
${ }^{26}$ Artículo IV-445:

«Procedimiento de revisión simplificado relativo a las políticas y acciones internas de la Unión.

1. El Gobierno de cualquier Estado miembro, el Parlamento Europeo o la Comisión podrán presentar al Consejo Europeo proyectos de revisión de la totalidad o parte de las disposiciones del Título III de la Parte III relativas a las políticas y acciones internas de la Unión.

2. El Consejo Europeo podrá adoptar una decisión europea que modifique la totalidad o parte de las disposiciones del Título III de la Parte III. El Consejo Europeo se pronunciará por unanimidad previa consulta al Parlamento Europeo y a la Comisión, así como al Banco Central Europeo en el caso de modificaciones institucionales en el ámbito monetario.

Dicha decisión europea sólo entrará en vigor después de haber sido aprobada por los Estados miembros, de conformidad con sus respectivas normas constitucionales.

3. La decisión europea contemplada en el apartado 2 no podrá aumentar las competencias atribuidas a la Unión por el presente Tratado».
} 
En este procedimiento la iniciativa no es del Consejo Europeo, sino que corresponde a los Estados miembros, al Parlamento Europeo o a la Comisión, como en el procedimiento ordinario de revisión. El procedimiento sólo puede afectar a las disposiciones del Título III de la Parte III y se indica expresamente que no puede utilizarse para aumentar las competencias atribuidas a la Unión por el Tratado Constitucional. EI Consejo Europeo podrá adoptar una decisión europea para modificar esas disposiciones, por unanimidad y previa consulta al Parlamento Europeo y a la Comisión (así como al Banco Central Europeo en el caso de modificaciones institucionales en el ámbito monetario).

En este supuesto, aunque se trate de un procedimiento simplificado, sí se contempla la previsión de ratificación por los Estados miembros, lo que le da una carácter convencional, de tal manera que la decisión europea sólo entrará en vigor después de haber sido aprobada por los Estados miembros, de conformidad con sus respectivas normas constitucionales. Nos situamos, por tanto, en una categoría híbrida entre el derecho interno (la decisión europea) y el internacional (el procedimiento de ratificación por los Estados), ya que la decisión europea debe ser objeto de ratificación por los Estados miembros. Por otro lado, no hay previsión alguna para el caso de que no todos los Estados ratifiquen, por lo que habría que entender aplicable, por analogía, la previsión del artículo 443.4.

También pueden considerarse como procedimientos de revisión, hasta cierto punto formalizados, aunque no figuren entre los artículos que se dedican específicamente a la revisión del Tratado constitucional, las cláusulas pasarelas previstas para las cooperaciones reforzadas. De acuerdo con el artículo 422, estas cláusulas pueden activarse por el Consejo tanto para el supuesto del paso de la unanimidad a la mayoría cualificada ${ }^{27}$, cuanto para pasar de procedimientos legislativos especiales al procedimiento legislativo ordinario ${ }^{28}$. Para activar estas cláu-

27 «1. Cuando una disposición de la Constitución que pueda aplicarse en el marco de una cooperación reforzada establezca que el Consejo debe pronunciarse por unanimidad, éste podrá, adoptar por unanimidad, de conformidad con lo dispuesto en el apartado 3 del artículo l-44, una decisión europea que establezca que se pronunciará por mayoría cualificada».

28 «2. Cuando una disposición de la Constitución que pueda aplicarse en el marco de una cooperación reforzada establezca que el Consejo debe adoptar leyes o leyes marco europeas con arreglo a un procedimiento legislativo especial, el Consejo podrá adoptar por unanimidad, de conformidad con lo dispuesto en el apartado 3 del artículo l-44, una decisión europea que establezca que se pronunciará con arreglo al procedimiento legislativo ordinario. El Consejo se pronunciará previa consulta al Parlamento Europeo". 
sulas pasarela no es necesario que intervenga el Consejo Europeo, sino que puede hacerlo el Consejo por unanimidad ${ }^{29}$. Tampoco hay previsión alguna de intervención de los parlamentos nacionales de los Estados integrados en la cooperación reforzada, a diferencia de lo que ocurre con las cláusulas pasarela del artículo 444. Por otra parte, estas cláusulas pasarela, como las del artículo 444, no son aplicables al ámbito de la defensa o a las disposiciones que tengan repercusiones militares $^{30}$.

Como se puede ver, la formulación de los procedimientos de reforma se queda también, como en el conjunto de las fuentes del Derecho, a medio camino en cuanto a su constitucionalización. Se sigue dando un protagonismo esencial a los Estados, de tal manera que la decisión unánime de éstos es esencial para poder seguir avanzando de manera sustancial en el proceso de integración. La incorporación de mecanismos constitucionales, que aleja claramente al Tratado Constitucional en este punto de su condición de Tratado, no llega a ser de entidad suficiente como para superar las deficiencias que se han evidenciado en el proceso de ratificación del Tratado y que pueden ser un obstáculo serio si se mantienen en los procedimientos de reforma.

\section{CONCLUSIONES}

El sistema de fuentes diseñado en el Tratado Constitucional está fuertemente condicionado (comenzando por la propia Constitución) por la tensión dialéctica entre ciudadanos y Estados, las dos fuentes de legitimación que la Constitución reconoce formalmente. Esa tensión dialéctica se mantiene en equilibrio en lo que se refiere a las fuentes legales y reglamentarias. Equilibrio adecuado, en principio, a las condiciones actuales del proceso de integración, por más que podía haberse avanzado algo más y con independencia de que en su aplicación prác-

29 Teniendo en cuenta que, de acuerdo con lo dispuesto en el artículo 1-44.3, «Todos los miembros del Consejo podrán participar en sus deliberaciones, pero únicamente participarán en la votación los miembros del Consejo que representen a los Estados miembros que participan en una cooperación reforzada" y que, también sobre la base de lo dispuesto en ese precepto, "La unanimidad estará constituida únicamente por los votos de los representantes de los Estados miembros participantes".

30 «3. Los apartados 1 y 2 no se aplicarán a las decisiones que tengan repercusiones militares o en el ámbito de la defensa". 
tica se oriente (si la Constitución entra en vigor) en mayor o menor medida hacia uno de esos dos polos.

Ha sido justamente la práctica la que ha conducido a la ruptura de ese equilibrio en la propia "Constitución" en cuanto fuente del Derecho, a través del proceso de ratificación diseñado en el Tratado Constitucional. La exigencia de unanimidad, propia de los Tratados y la combinación de procesos refrendatarios frente a otros basados en la mera ratificación parlamentaria han conducido a una situación de conflicto abierto de legitimidades. Por un lado, la legitimidad de los Estados, manifestada a través de sus representantes democráticos, que firmaron el Tratado Constitucional. Por otro lado la legitimidad de los ciudadanos, manifestada por medio de los procesos refrendatarios que, pese a su carácter parcial y minoritario respecto del conjunto de los ciudadanos de la Unión, adquiere una dimensión desproporcionada debido a la entidad de los países a los que ha afectado.

Este conflicto estaba ya latente en las propias previsiones del Tratado, como evidencia la Declaración relativa a la ratificación del Tratado por el que se establece una Constitución para Europa, y la fórmula similar que, para el futuro, contempla el artículo $443.4 \mathrm{CEu}$. Sin embargo, el hecho de que haya afectado a dos Estados especialmente importantes en el proyecto europeo, le ha dado al conflicto una entidad especial, que amenaza con impedir la culminación del proceso de ratificación. La manifestación radical del conflicto evidencia que las previsiones normativas no han sido las adecuadas y que es necesario partir de otros planteamientos para los procesos de reforma futuros (si la ratificación se produce) o para procesos de ratificación futuros (si la actual finalmente no puede culminarse).

No cabe duda de que la situación ideal y más acorde con los planteamientos del federalismo democrático actual sería la de un referéndum a nivel europeo. No obstante, si esta opción no se impone por suponer una decantación absoluta por los ciudadanos sobre los Estados en la tensión dialéctica del incipiente federalismo europeo, se podrían articular otras soluciones menos avanzadas. Una ratificación conjunta del Parlamento europeo y de los parlamentos estatales podría tomarse como punto de partida. Obviamente la ratificación de los parlamentos estatales no debería basarse tampoco en la regla de la unanimidad de los Estados. Tendría que establecerse una mayoría cualificada (de dos tercios, por ejemplo). En esas condiciones, cabría plantearse también la propia legitimidad del uso del referéndum cuando no es una exigencia constitucional interna, dadas las disfunciones que provoca su uso parcial (cuestión distinta, sería su utilización a nivel europeo, como ya he indicado). 
La corrección en los procedimientos de ratificación no resolvería todos los problemas que afectan al proceso de constitucionalización de la Unión Europea. El contenido de la Constitución ha sido, en realidad, el motivo que ha dado lugar al conflicto de legitimidades. En la Unión se han adoptado opciones constitucionales discutidas (ampliación) antes de la elaboración del Tratado Constitucional. y el texto del Tratado contiene también opciones constitucionales que no todos los europeos comparten. En una comunidad constitucional consolidada, estos conflictos se resolverían dentro del marco constitucional. En la medida en que la Unión se siga situando en un escenario preconstitucional y no se dote de los procedimientos adecuados para adoptar las decisiones fundamentales que debe adoptar, los conflictos pueden estancarse dando lugar a una crisis grave y a un retroceso del proceso de integración. 